\title{
The Effects of Perceived Organizational Support on Innovative Performance of High School Football Players: The Mediating Role of Self-Management
}

\author{
Eunah Hong ${ }^{1}$ and Yejee Jeong ${ }^{2 *}$ \\ ${ }^{1}$ Division of Kinesiology \& Sport Studies, Ewha Womans University, Seoul, Korea \\ ${ }^{2}$ Interdisciplinary Studies, Yuhan University, Gyeonggi, Korea
}

\author{
Article Info \\ Received 2021.07.20. \\ Revised 2021.09.10. \\ Accepted 2021.09.17. \\ Correspondence* \\ Yejee Jeong \\ yjjeong0920@yuhan.ac.kr \\ Key Words \\ Perceived Organizational \\ Support, \\ Innovative Performance, \\ Self-Management, \\ High school Football Players
}

PURPOSE The purpose of this study was to investigate the effects of perceived organizational support of high school football players on innovative performance. Of particular note, we focused on examining the mediation effect of self-management between perceived organizational support and innovative performance. METHODS A total of surveys returned was 137 and the data used for the final analysis was 130. The data was processed using SPSS 21.0 statistical program and Lisrel 9.2 for confirmatory factor analysis. RESULTS The results of the analysis were as follows: first, perceived organizational support of high school football players had a positive effect on players' self-management. Second, players' self-management had a positive effect on players' innovative performance. Third, players' self-management fully mediated between perceived organizational support and players' innovative performance. CONCLUSIONS The study concluded that maximizing both perceived organizational support and self-management of the high school football players are necessary in order for the organization to achieve high level of innovative performance.

\section{서론}

본 연구는 고등학교 축구 선수들의 혁신성과가 어떠한 과정을 통해 창 출될 수 있는가? 라는 근본적인 질문에서 시작된다. 선행 연구들에 의 하면 조직 문화(Kotter \& Heskett, 1992; Lee \& Tseng, 2005; Meng \& Berger, 2019), 리더십(Meng \& Berger, 2019; Paais \& Pattiruhu, 2020), 조직후원인식(Kristiani et al., 2019) 등 다양한 조직 차원의 변 수들이 일련의 메커니즘을 통해 조직 효과성을 높이는 것으로 알려져 있다.

조직의 문화, 분위기, 협업과 팀워크의 정도 등은 가시적이지 않으나 조직의 효과성에 영향을 행사하는 대표적 조직 자본(organizational capital)이다(Kaplan \& Norton, 2004). 이에 본 연구에서는 조직이 얼 마나 지원적인 분위기를 창출하고 있는가의 정도, 즉 고등학교 축구 선 수들이 인지한 조직후원인식이 혁신성과에 미치는 영향력을 알아보고 자 한다.

스포츠 팀을 비롯한 조직에서 혁신은 경쟁우위를 점하거나 유지하는 중요한 요소이며(Barnhill \& Smith, 2019), 조직의 생존에도 영향을 미 칠 수 있는 요인이기에 리더를 포함한 조직 구성원 모두에게 혁신은 중 요한 화두이다(Nam \& Cheong, 2017). 특히 고등학교 대회에서의 성
적이 선수들의 대학 진학과 연결되어 있는 우리나라 실정을 고려할 때 팀의 성과, 더 나아가 팀의 존속 여부에도 영향을 미칠 수 있는 혁신이라 는 변수는 학술적으로도 지속적인 관심, 연구가 필요하다고 판단된다. 스포츠 팀에서 혁신은 선수들이 자신의 기량을 향상시키기 위해 새로운 변화를 추구하는 개인적 수준의 행동으로 나타날 수도 있고, 팀 차원에 서는 기존해 해 왔던 플레이와 다른 플레이를 시도하거나 새로운 방식의 훈련을 도입하는 것 등으로 표출된다(Ratten, 2016).

이처럼 혁신이란 21세기 현 상황에서 필수적인 요소로 언급되고 있 으나 실제 조직에서의 혁신은 근본적으로 높은 불확실성(uncertainty) 과 실패가능성을 지닌다. 따라서 구성원들이 혁신성과에 이르는 과정에 서 '우리 조직은 혁신을 시도하는 과정을 이해하고 지원한다'는 사회·심 리적 지원을 인지할 때라야 구성원들의 불안감이 해소되고 새로운 아이 디어 도입을 두려워하지 않을 것이다(Amabile et al., 1996; Gupta \& Barua, 2016; Janssen, 2005). 내가 속한 조직이 나의 조직에 대한 기 여를 인정하고 구성원 개개인을 배려한다는 인식은 구성원들을 내재적 으로 고무시키고 창의성과와 혁신성과를 높인다(Amabile et al., 1996). 이에 본 연구에서는 조직후원인식이 혁신성과에 미치는 영향력을 고등 학교 축구 팀 선수들을 대상으로 검증해보고자 한다.

한 발 더 나아가 본 연구에서는 조직후원인식이 혁신성과에 영향을 미 
치는 과정에서 선수들의 자기관리가 매개변수의 역할을 할 것이라 주장 한다. 조직 차원의 심리적 지원을 받고 있다는 안정감과 정서적 지지에 대한 확신은 조직에 대한 긍정적 태도를 형성할 것이다. 구성원들과 혁 신성과 창출에 후원적인 조직 환경은 구성원의 자기 결정성과 자기 효능 감을 높이며(Eisenberger et al., 1986) 이는 자기관리에도 긍정적 영향 력을 행사할 것으로 사료된다.

조직후원인식은 조직에서 일어나는 혁신행동의 선행변인이라는 점이 Gupta \& Barua(2016)의 연구에서 밝혀진 바 있다. 조직에서 구성원의 긍정적인 감정은 구성원들의 생각과 행동의 다양성을 촉진하여 혁신행 동으로 이어지게 한다(Woo \& Kim, 2021). 조직후원인식이란 '조직이 나의 조직에 대한 기여를 제대로 평가하고 나를 가치있게 여긴다'고 느 끼는 구성원들의 인지 정도이다(Eisenberger et al., 1986). 구성원들은 내가 속한 조직이 나의 가치를 인정하고 배려한다고 인식할 때 조직에 대한 신뢰 정도를 높이게 되는데 조직의 후원은 일반적으로 공식적/비 공식적 그리고 유형/무형적 보상(예: 칭찬, 멘토링, 승진, 급여 인상, 교 육 기회 제공 등) 등을 통해 표출된다(Jung \& Takeuchi, 2018).

스포츠 분야의 조직후원인식을 다룬 해외 연구를 살펴보면 심판을 대 상으로 한 연구(Choi \& Chiu, 2017; Hong et al., 2019; Livingston \& Forbes, 2016; 2017), 프로 선수들을 대상으로 한 연구(Ströbel et al., 2018)가 존재한다. 국내 연구로는 국가대표 및 상비군 선수들의 조직후 원인식이 경기력에 미치는 영향에 관한 연구(Oh et al., 2019), 스키 강 사들을 대상으로 한 연구(Byeon, 2010) 등을 발견할 수 있다. 그러나 고 등학교 축구 팀 선수들이 인식한 조직후원인식이 자기관리라는 매개변 수를 통해 혁신성과에 이르는 프로세스를 살펴본 연구는 찾기 힘든 실정 이다.

이에 축구 선수로서의 커리어 정립 여부와 관련한 극도의 스트레스를 받는 고등학교 선수들(Kim et al., 2019)을 대상으로 사회·심리적 지원 이 혁신성과에 미치는 영향력과 그 과정을 살펴보는 실증연구는 가치가 있을 것으로 판단하였다. 대학 진학, 프로(K1, K2), 세미프로(K3, K4) 진출 등과 관련한 심리적 부담감이 큰 고등학생 선수에 대한 조직 차원 의 진정한 배려는 학생으로 하여금 조직, 팀 직무는 물론 축구 관련 과업 에 몰입하게 하는 중요한 동기가 되기 때문이다. 조직, 혹은 조직의 리더 인 감독과 코치가 선수 개개인의 활동에 관심을 가지고, 자기개발과 진 로 등에 다양한 지원을 해준다고 선수들이 인식하게 되면 더욱 혁신적 플레이가 표출될 수 있을 것이다.

조직후원인식이 높은 구성원들은 낮은 구성원들에 비해 조직에 대한 헌신도가 한층 더 높고 본인이 담당하는 업무에도 만족감이 더 높기에 (Ko et al., 2019) 경기력 향상, 승리, 우승 등의 성과 창출에 대한 고민 이 필수적인 엘리트 스포츠 조직에서 선수들이 지각하는 조직후원인식 에 대한 연구의 필요성이 제기된다. 특히 고등학교 축구선수들이 소속 된 조직이 선수들을 가치있게 여기고 선수들의 복지를 위하여 관심을 보 인다면 선수들 역시 팀의 배려에 상응하는 자기관리를 할 것이라 유추할 수 있다. 스포츠에서 최정상의 경기수행능력을 나타내기 위해서는 철저 한 자기관리가 뒷받침되어야 하는 것은 자명한 사실이기 때문이다(Kim, 2016). 따라서 본 연구의 가설 1 은 다음과 같다.

가설 1 . 고등학교 축구 선수들이 인지한 조직후원인식은 선수들의 자 기관리에 긍정적 영향을 미칠 것이다.

자기관리란 선수로서의 개인이 성공적 수행에 도달하기 위해 행동을 유지하고 변화시키는 노력으로 자신을 조절하는 행동이다(Jones et al., 1977). 부정적 생각 조절, 신체적 스킬을 향상시키기 위한 훈련 계획, 긴
장 수준 통제, 타인과의 긍정적 관계 유지 등이 포함된 자기관리 역량이 높은 운동선수들은 구체적인 목표를 달성하기 위한 행동들을 보다 자신 있게 한다(Kim \& Cruz, 2021).

운동선수의 자기관리 중요성은 크리스티나우 호날두(Cristiano Ronaldo)를 통해 살펴볼 수 있을 것이다. 2003년 마른(skinny) 몸으로 맨체스터 유타이티드에 입단한 호날두는 유산소, 웨이트 훈련 뿐만 아니 라 취침, 기상 시 습관적으로 하는 코어 운동 루틴, 영양 전문가가 제공 하는 고단백, 통밀/과일/야채를 중심으로 하되 설탕을 피하는 1 일 6식 의 식단을 철저하게 지킨다(Platt, 2021). 1 일 8시간 수면이라는 전통적 패턴에서 벗어나 90 분 간의 수면을 5 번에 나누어 하는 방식, 훈련을 하 지 않을 때에도 편안하고, 심이 있는 라이프스타일을 유지하면서 심리적 안정을 취하는 방법 역시 주목을 끈다(Platt, 2021). 공부와 운동을 병행 하는 학생선수에게 자기관리의 범위는 학업 뿐만 아니라 훈련, 팀 동료 및 일반학생들과의 관계를 포함하며 자기관리의 한 부분이라도 문제가 발생할 경우 운동 기량에도 부정적인 영향이 나타나기 마련이다(Son \& Cho, 2020).

혁신행동은 일반적으로 조직의 공식적 평가, 보상으로 간주되지 않기 에 구성원의 내재적 동기부여 여부가 중요한 역할을 한다(Kim et al., 2016). 조직에서 혁신행동이 실행되기 위해서는 상호 신뢰가 전제되어 야 하는데(Chung, 2006) 고등학교 축구팀의 경우 지도자가 선수들의 신뢰를 얻게 되면 선수들의 혁신행동을 기대할 수 있고 궁극적으로 팀의 목표 성취에 다다를 수 있을 것이다( $\mathrm{Ha}, 2020)$. 스포츠 개발 및 평화 기 관 종사자를 대상으로 진행한 Svensson et al.(2019)의 연구에서는 조 직의 구성원들을 이동, 배치하는 인적자원 역량을 향상시킬 때 공유리더 십이 발현되고, 궁극적으로 이는 혁신적인 근무행동으로 이어진다고 주 장한다.

지식노동자들의 자기관리역량이 혁신행동에 긍정적인 영향을 미쳤다 는 점을 실증적으로 규명한 Li e al.(2018)의 연구에 근거하여 세운 가설 2는 다음과 같다.

가설 2. 고등학교 축구 선수들의 자기관리는 혁신성과에 긍정적 영향 을 미칠 것이다.

본 논문에서는 선수들이 인지한 조직후원인식이 혁신성과에 영향을 미치는 과정에서 자기관리가 매개역할을 할 것임을 검증하고자 한다. 온 전히 선수 개인만이 노력을 하는 경우와 달리 내가 속한 조직이 본인의 가치를 인정하고, 조직 차원에서 관심을 가져준다는 믿음은 선수들이 자 기관리를 하는 과정에서 용기를 복돋아주는 촉매제의 역할을 할 것이라 유추 가능하다.

본 연구에서 다루는 조직후원인식 - 자기관리 - 혁신성과의 프로세스 를 살펴보는 선행연구는 찾아보기 힘든 실정이다. 그러나 조직 효과성 을 논하는 I-P-O (Input-Process-Output)(Cohen \& Bailey, 1997) 모 델 관점에서 보았을 때 조직후원인식은 조직 특성인 Input(투입), 선수 의 자기관리는 조직후원인식을 통해 선수가 인식하는 집단생활에서의 Process(과정), 혁신성과는 Output(결과)으로 볼 수 있을 것이다. 이에 근거하여 세운 가설 3 은 다음과 같다.

가설 3. 고등학교 축구 선수들이 인지한 조직후원인식이 혁신성과에 영향을 미치는 과정에서 자기관리가 매개역할을 할 것이다.

지금까지 논의된 결과들을 기반으로 실증연구를 위한 연구 모형을 〈Fig. 1〉에 제시하였다. 


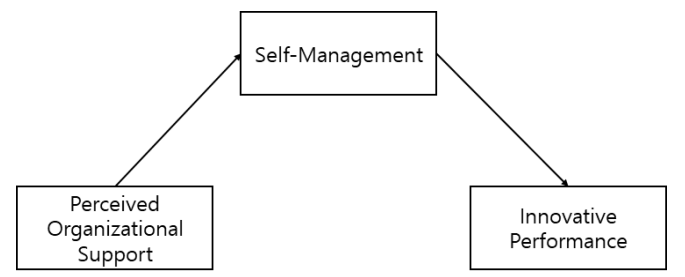

Fig. 1. A Research Model

\section{연구방법}

\section{연구대상}

본 연구의 가설을 검증하기 위해 2021년 3월부터 4월까지 4개 고등학 교 축구팀 선수들을 대상으로 설문을 실시하였다. 연구 초기에, 각 팀의 지도자들에게 전화로 연구의 목적을 설명하였고 협조를 얻은 후 설문 지를 배포하였다. 137 부의 설문지를 회수하였으며 그 중 130 부를 최종 분석에 활용하였다. 응답자는 모두 남자였으며 연령 평균은 16.6세(최 저 15세, 최고 19세), 평균 선수 경력은 10.7년으로 나타났다(최저 6년, 최고 15년).

\section{측정 항목 및 방법}

가설 검증을 위해 설문지의 모든 문항은 리커트 척도(5점)로 구성하였 다. 선수연령 및 경력에 대한 문항과 함께 자기관리, 조직후원인식, 혁 신성과 관련 문항으로 설문지를 구성하였으며 측정 항목은 〈Table 1〉 과 같다.

1. 조직후원인식 (Perceived Organizational Support)

본 연구에서 조직후원인식의 조작적 정의는 '우리 조직이 진정으로 선 수들을 아끼고 선수들의 공헌을 제대로 평가한다고 인지하는 정도'이다. 기존 연구에서 가장 빈번히 인용되는 Eisenberger et al.(1986)의 조직

Table 1. List of measurement

\begin{tabular}{cc}
\hline & Variables \\
\hline Control Variable & Age, Grade, Years as a Player \\
Independent Variable & Perceived Organizational Support \\
Mediating Variable & Self-Management \\
Dependent Variable & Innovative Performance \\
\hline
\end{tabular}

Table 2. CFA loading values for research variables

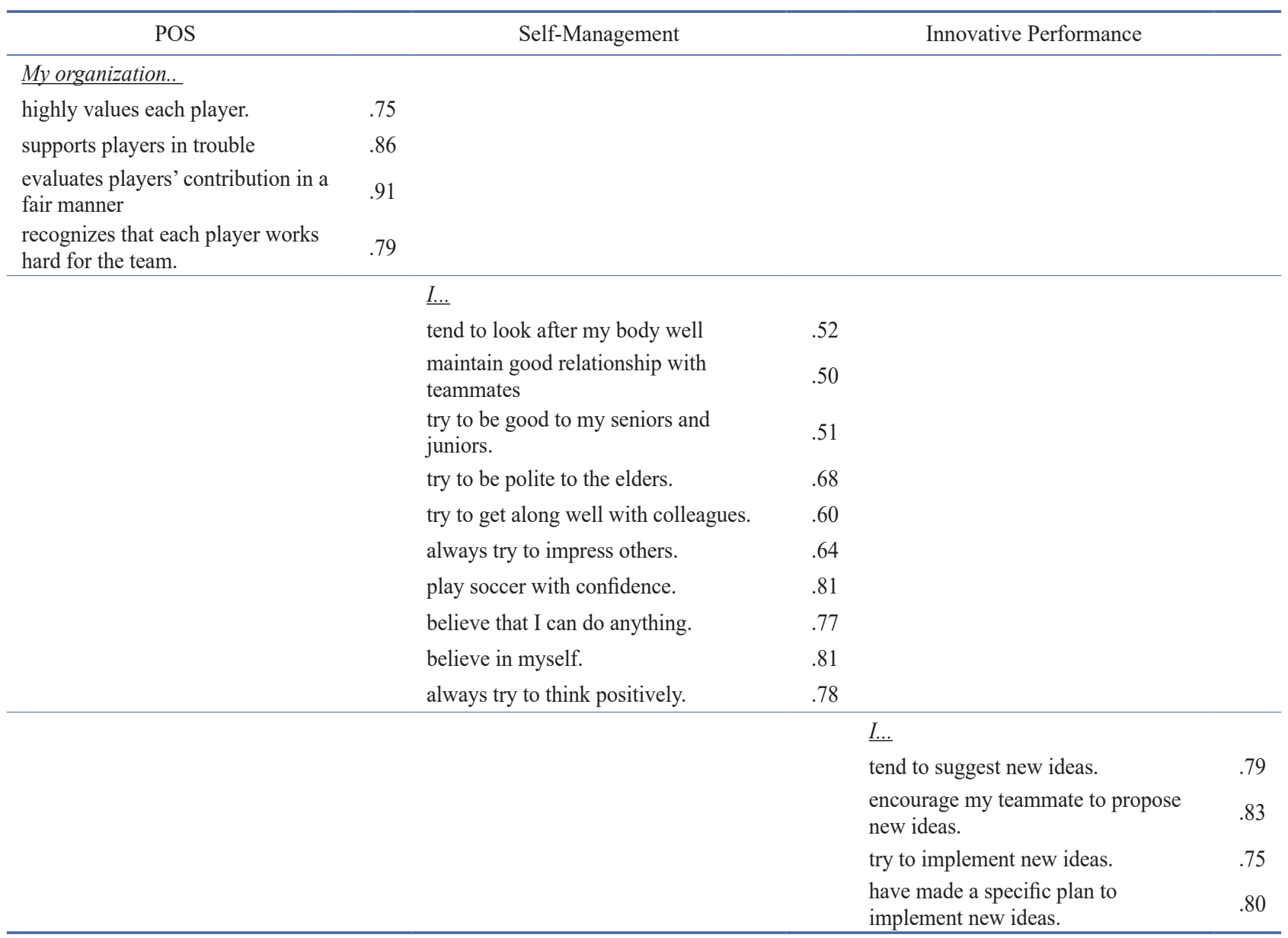

Chi-square $=346.98($ degree of freedom $=132), \mathrm{NFI}=.87, \mathrm{CFI}=.91, \mathrm{IFI}=.92, \mathrm{GFI}=.73$ 
후원인식 문항을 고등학교 축구 선수들이 처한 맥락에 맞게 변형하여 4 문항을 사용하였으며 대표 문항으로는 "우리 조직은 선수 한 명 한 명을 정말 아끼고 있다는 생각이 든다," “우리 조직은 선수 각자가 조직에 기 여하는 부분을 공정하게 평가하는 편이다.” 등이 있다.

\section{2. 자기관리}

자기관리란 '선수들이 변화하기 위한 노력으로 스스로 처한 환경과 행 동 결과를 조정하고 관리하는 정도'로 정의된다(Jones et al., 1977). 한 국 운동 선수들의 자기관리를 위해 개발된 $\operatorname{Huh}(2003)$ 의 운동선수 자기 관리 검사지(ASMQ)를 축구 맥락에 맞게 수정하여 활용하였으며 대표적 문항으로는 "나는 내 자신을 믿는다," "나는 무엇이든 할 수 있다는 생각 을 가지고 있다.” 등이 있다.

\section{3. 혁신성과}

혁신성과란 '조직의 문제 해결을 위해 변화를 시도하고 혁신적 아이디 어를 제시 및 실행하는 정도'로 조작적 정의된다. Scott \& Bruce(1994) 의 혁신문항을 축구선수들의 맥락에 맞게 수정하여 활용하였으며 대표 적 문항으로는 "나는 새로운 아이디어를 제시하는 편이다," "나는 팀 동 료에게도 새로운 아이디어를 내라고 권장하는 편이다.” 등이 있다. 마지 막으로 선수들의 연령과 선수 경력, 학년을 통제변수로 채택하였다.

\section{4. 통계 처리}

본 연구의 가설 검증을 위해 측정한 모든 변수들의 값은 SPSS PC+ for Windows (version 21.0) 통계 프로그램을 이용하여 신뢰도 검사, 다중공선성 검사, 상관관계 분석 및 회귀분석을 실시하였다. 한편 Lisrel (version 9.2) 구조방정식모형을 통해 변수 측정 아이템들의 CFA 값을 제시하였다.

본격적인 가설 검증에 앞서 연구 변수들의 타당도를 검증하기 위해 Jöreskog \& Sörbom(2002)의 절차를 따라 CFA를 실시하였다. 설문지 에 포함되었으나 문항의 적재치가 . 40 이하인 자기관리 문항 8 문항, 혁 신성과 2 문항이 탈락되어 최종적으로 자기관리 문항 10 문항, 조직후원

Table 3. Means, S.D., Reliability, and Correlation among variables

\begin{tabular}{lccccc}
\hline & Mean & S.D. & $(1)$ & (2) & (3) \\
\hline (1) POS & 3.96 & .76 & $(.896)^{2}$ & & \\
\hline (2) Self-Mgt & 4.03 & .51 & $.45^{* * * 1}$ & $(.886)$ & \\
\hline (3) Innovative Performance & 3.62 & .62 & $.32^{* * *}$ & $.48^{* * *}$ & $(.872)$ \\
\hline
\end{tabular}

$* * * \mathrm{p}<.001$, Reliability is in parentheses.
인식 4문항, 혁신성과 4문항이 채택되었다. CFA 결과 적재치는 〈Table 2)에 기재하였다.

자기관리의 탈락 문항은 "나는 잠을 충분히 자는 편이다," "나는 시합 전 음식을 조절하는 편이다," "나는 체력 훈련을 열심히 하는 편이다," "나는 규칙적으로 개인 훈련을 한다" 등이다. 최종 선택된 자기관리 문 항이 "나는 자신감을 가지고 축구에 임한다," "나는 내 자신을 믿는다" 등 정신적 부분을 강조한다면 탈락된 문항은 상대적으로 신체적 자기 관 리를 강조하는 문항이라 판단된다.

한편 혁신성과의 탈락 문항은 "나는 새로운 기술을 배우기 위해 노 력하는 편이다," “우리 팀 훈련 시간은 짧지만 내용이 알차다.”이다. 최 종 선택된 혁신성과 문항은 "나는 새로운 아이디어를 제안하는 편이다," “나는 새로운 아이디어를 직접 실행하기 위해 노력한다." 등으로 새로운 아이디어의 제안, 권장, 계획과 실행에 대한 내용이다. 이에 본 연구에 응답한 학생들은 새로운 아이디어의 제시와 실행을 혁신성과로 간주하 였다고 판단하였다.

이후 확정된 문항을 대상으로 Cronbach alpha 값을 이용한 신뢰도 분 석을 실시하였으며 〈Table 3〉 와 같이 모두.8이상의 값이 도출되었다.

한편 회귀모형을 검정하기 이전에 다중공선성 확인을 위해 공선성 통 계량 역시 살펴보았으며 모든 변수들 간의 VIF는 3.1을 넘지 않았으며 이는 기준이 되는 10 보다 확연히 낮은 수치이다.

\section{연구결과}

구성원들이 인지한 조직후원인식이 자기관리 및 혁신성과에 미치는 영향력을 알아보고 가설을 검증하기 위해 SPSS PC+ for Windows (version 21.0)를 활용하여 Baron \& Kenny(1986)의 매개분석 3단계를 진행한 결과는 〈Table 4>와 같다.

첫째, 독립변수가 매개변수에 통계적으로 유의한 영향을 미치는가를 검증하였다. 선수들이 인지한 조직후원인식은 자기관리에 통계적으로 유의한 정 $(+)$ 의 영향을 미치는 것으로 나타났다( $\beta=.459, p<.001)$. 이는 Baron \& Kenny(1986)의 매개검증 첫 단계를 만족시켰기에 선수들의 조직후원인식이 자기관리 정도에 긍정적 영향을 미칠 것이라는 가설 1 이 지지되었다.

둘째, 본 연구의 매개변수인 선수들의 자기관리 정도가 종속변수인 혁 신성과에 통계적으로 유의한 영향력을 미치는 것 역시 확인하였다. 자 기관리는 혁신성과에 통계적으로 유의한 정 $(+)$ 의 영향을 미쳤으며 $(\beta$ $=.425, p<.001)$ 선수들의 자기관리 정도가 혁신성과에 긍정적 영향을 미칠 것이라는 가설 2 역시 지지되었다.

마지막으로 독립변수와 매개변수 모두를 회귀식에 투입하였을 때 종

Table 4. Results of Regression Analysis

\begin{tabular}{|c|c|c|c|c|c|c|c|c|c|c|c|c|}
\hline & \multicolumn{4}{|c|}{$\begin{array}{c}1^{\text {st }} \text { Step } \\
\text { DV: Self-Management }\end{array}$} & \multicolumn{4}{|c|}{$\begin{array}{c}2^{\text {nd }} \text { Step } \\
\text { DV: Innovative Performance }\end{array}$} & \multicolumn{4}{|c|}{$\begin{array}{c}3^{\text {rd }} \text { Step } \\
\text { Testing for Mediation } \\
\text { DV: Innovative Performance }\end{array}$} \\
\hline & B & S.E. & $\beta$ & $\mathrm{t}$ & B & S.E. & $\beta$ & $\mathrm{t}$ & B & S.E. & $\beta$ & $\mathrm{t}$ \\
\hline POS & .307 & .054 & $.459 * * *$ & 5.727 & & & & & .101 & .073 & .124 & 1.376 \\
\hline Self-Management & & & & & .588 & .099 & $.483 * * *$ & 5.937 & .516 & .112 & $.425 * * *$ & 4.630 \\
\hline Adjusted $\mathrm{R}^{2}$ & \multicolumn{4}{|c|}{.220} & \multicolumn{4}{|c|}{.220} & \multicolumn{4}{|c|}{.226} \\
\hline
\end{tabular}


속변수인 혁신성과에 대한 독립변수의 영향력을 살펴보았다(Baron \& Kenny, 1986). 가설 3은 앞서 검증한 두 가설에 의거하여 고등학교 축 구 선수들이 인지한 조직후원인식이 자기관리 정도를 매개로 하여 혁신 성과에 영향을 미치는지의 매개효과를 확인하는 것이다.

〈Table 4〉에서도 볼 수 있듯이 1단계에서는 유의했던 조직후원인식 의 종속변수에 대한 영향력이 $(\beta=.459, p<.001)$ 매개변수인 자기관리가 함께 회귀식에 투입된 상태에서는 통계적으로 유의하지 않은 것으로( $\beta$ $=.124$, n.s.) 나타나 선수들의 자기관리 정도가 조직후원인식과 혁신성 과와의 관계를 완전 매개(full-mediation)하는 것으로 나타났다. 이로써 선수들이 인식한 조직후원인식과 혁신성과와의 관계를 자기관리가 매개 할 것이라는 가설 3 은 지지되었다.

이러한 매개효과를 다시 한 번 검증하기 위해 소벨 테스트 역시 실시 하였다(Sobel, 1986). 소벨 테스트 결과 .357(p〈.001)의 값이 도출되었 으며 자기관리의 매개효과는 유의한 것으로 밝혀졌다.

\section{논의}

본 연구는 고등학교 축구선수들이 지각한 조직후원인식과 자기관리 및 혁신성과와의 인과관계를 확인하는데 그 목적이 있다. 연구의 결과를 바 탕으로 논의를 진행하고자 한다.

첫째, 고등학교 축구선수들이 지각한 조직후원인식은 구성원의 자기 관리에 긍정적 영향을 미치는 것으로 나타났다. 이는 IT 기업 구성원들 이 인식하는 조직후원인식이 구성원 개개인의 커리어 자기관리를 향상 시켰다는 Yogalakshmi \& Suganthi(2020)의 연구를 지지하는 결과이 다. 사회교환의 개념을 통해 조직후원인식은 조직 효과성에 영향을 미 치며(Loi et al., 2006) 조직후원의 정도를 높게 인지한 선수들은 조직 에 보다 긍정적인 응답을 할 가능성이 높다(Cropanzano et al., 2017). 선수들은 본인이 조직으로부터 받는 지지에 부응하기 위해 자기관리를 통해 경기에 몰입할 것이고, 특히 긍정적 상호작용에 대한 믿음을 가진 구성원들은 낙관적이고 주도적인 행동을 보인다(Cropanzano et al., 2017)는 점에서, 선수들이 조직으로부터 지지받고 있다는 인식을 지속 적으로 가질 수 있도록 하는 전략 고민이 필요할 것으로 판단된다.

고등학교 축구팀에서의 조직후원인식 강화 방안으로는 부상 등으로 인한 중도탈락 위기에 항상 노출되어 있는 학생선수들에게 훈련 및 대회 참여 이외에도 지도자/심판 자격증, 영어/컴퓨터 자격증 취득, 전문 기 술 교육 등을 적극적으로 지원하여(Stambulova et al., 2015; Ströbel et al., 2018) 고등학교 졸업 후 어느 분야에서든지 사회인으로서 살아갈 수 있는 기반을 마련해 주는 예를 들 수 있겠다.

둘째, 고등학교 축구선수들의 자기관리는 조직의 혁신성과에 긍정적 영향을 미친다. 이는 한국 여자골프 선수들의 자기관리가 선수의 경기력 에 정적 영향을 행사한다는 Hwang \& Chun(2013)의 연구, 자기관리가 올림픽 대표선수 및 대표선수 경력이 있는 선수들의 최고기록 달성에 미 치는 긍정적 영향력을 검증한 Orlick \& Partington(1988)의 연구 결과 와 유사한 맥락이다.

Kim \& Cruz(2021)가 수행한 연구에서는 태권도 선수들이 각성 수 준을 조절하고 훈련에서의 고통을 참기 위한 자기관리 전략으로 긍정적 셀프 토크(self-talk), 호흡법, 명상 등의 전략을 제시한 바 있다(Kim \& Cruz, 2021). 격투기와 구기운동의 차이는 존재하지만 신체적, 정신적 으로 극한의 단계를 경험하고 매일 자신과의 싸움을 계속해야 하는 것이 엘리트 선수들의 공통적인 삶이라는 점에서 언급한 자기관리 전략은 참 고할 만하다.
혁신이란 단순히 창의적인 아이디어를 생각해내는 것과 다르다 (Levitt, 2002). 아이디어 창출에서 한 발 더 나아가 조직 목표를 달성 (goal striving)하는 구체적 노력과 행동이 함께 동반되는 것이 바로 혁 신인 것이다(Levitt, 2002; Ng \& Lucianetti, 2016). 결과적으로 팀의 승리라는 구체적 목표를 실현하기 위해 주특기 기술의 향상, 자신있는 플레이를 위한 기술 연마 등의 구체적 행위가 혁신으로 이어진다고 할 수 있다. 뛰어난 적응력과 스트레스 대처 능력을 지닌 고등학교 축구선 수들에게도 조직 차원에서 개인의 진로 설정에 대한 관심을 보이고, 지 지를 보내는 것은 선수들의 혁신행동에 긍정적인 영향을 미칠 수 있다 (Kang, 2019).

셋째, 조직후원인식은 선수들의 자기관리를 매개로 하여 조직의 혁신 성과를 창출하는 것으로 나타났다. 선수들은 각자의 기여도와 활동에 대 해 인정받고 있다는 조직후원인식이 구성원의 자기관리에 영향을 미치 며, 이러한 구성원의 자기관리가 뒷받침 되어야만 혁신성과를 거둘 수 있음을 시사한다.

축구는 집단 스포츠의 대표격이며 효과성을 제고시키기 위해 개인 의 출중한 플레이와 함께 팀 플레이를 강조한다. 리오넬 메시(Lionel Messi)와 같은 세계 최고 선수도 2021년 7월 Euro 2020에서 만 34세 의 나이로 성인 세계대회 첫 트로피를 들어 올렸다는 점은 축구가 한 명 의 스타 선수로 성과를 거둘 수 있는 스포츠가 아니라는 점을 방증한다. 팀의 전폭적인 지지가 구성원들에게 전달되고, 선수각자가 최고의 자기 관리를 통해 높은 수준의 수행력과 혁신행동을 실행할 때 비로소 팀이 목표로 한 성과가 창출되는 것이다.

\section{결론 및 제언}

본 연구에서는 고등학교 축구선수들이 인지하는 조직후원인식이 혁신 성과로 이어지는 과정에서 자기관리의 완전매개 역할을 규명하였다. 이 는 선수들의 조직후원인식 수준이 높다고 해서 직접적으로 혁신성과로 이어지는 것을 기대할 수 없다는 점, 고등학교 축구팀 차원에서 선수들 의 조직후원인식과 함께 선수들의 자기관리를 극대화하는 방안이 필요 하다는 것을 의미한다. 다시 말해서 팀이 선수들에게 지원적이더라도 그 사회·심리적 지원이 선수들의 자기관리 노력으로 이어질 때라야 성 과창출이 가능함을 시사한다. 이러한 학문적, 실무적 기여에도 불구하 고 본 연구의 제한점은 다음과 같다.

첫째, 본 연구는 시간상의 문제를 고려하지 못한 채 횡단연구로 진행 되었다. 조직후원인식이 선수들에게 전달되고 그 영향력이 발휘되는 데 에는 다소의 시간이 요구될 것이다. 따라서 추후 연구에서는 종단 연구 를 통한 조직후원인식의 영향력을 검증할 필요가 있다.

둘째, 본 연구에서는 고등학교 축구 팀의 혁신성과에 긍정적 영향을 미치는 변수로서 조직후원인식과 자기관리만을 살펴보았다. 그러나 추 후 연구에서는 혁신성과에 영향을 미치는 것으로 밝혀진 변혁적 리더 십, 집단 스포츠인 축구 맥락에서의 $\mathrm{We}$-리더십 등의 리더십 변수, 긍정 심리자본과 커리어 자기관리 등의 보다 다양한 팀 및 조직 관련 프로세 스 변수들을 발굴하여 효과성에 기여하는 다양한 변수들을 검증해야 할 것이다. 


\section{참고문헌}

Amabile, T. M., Conti, R., Coon, R., Lazenby, J., \& Herron, M. (1996). Assessing the work for environment for creativity. Academy of Management Journal, 39(5), 1154-1164.

Baron, R. M., \& Kenny, D. A. (1986). The moderator-mediator variable distinction in social psychological research: Conceptual, strategic, and statistical considerations. Journal of Personality and Social Psychology, 51(6), 1173-1182.

Barnhill, C. R., \& Smith, N. L. (2019). Psychological contract fulfillment and innovative work behaviours of employees in sport-based SBEs: the mediating role of organisational citizenship. International Journal of Sport Management and Marketing, 19(1-2), 106-128.

Byeon, K. (2010). Structural relationship among POS(perceived organization support), TMX(team-member exchange) and customer orientation for ski school lecturer: organization trust, cowork trust, job satisfaction, organization commitment as mediating variables. Korean Society for Sport Management, 15(6). 67-82.

Choi, H., \& Chiu, W. (2017). Influence of the perceived organizational support, job satisfaction, and career commitment on football referees' turnover intention. Journal of Physical Education and Sport, 17(3), 955-959.

Chung, D. (2006). The influence of the knowledge sharing and its antecedent factors on the innovative behavior. Journal of the Korean Data Analysis Society, 8(5), 2063-2080.

Cropanzano, R., Anthony, E. L., Daniels, S. R., \& Hall, A. V. (2017). Social exchange theory: A critical review with theoretical remedies. The Academy of Management Annals, 11(1), 479-516.

Cohen, S. G., \& Bailey, D. E. (1997). What makes teams work: Group effectiveness research from the shop floor to the executive suite. Journal of Management, 23, 239-290.

Eisenberger, R., Huntington, R., Hutchison, S., \& Sowa, D. (1986). Perceived Organizational Support. Journal of Applied Psychology, 71(3), 500-507.

Gupta, H., \& Barua, M. K. (2016). Identifying enablers of technological innovation for Indian MSMEs using best-worst multi criteria decision making method. Technological Forecasting and Social Change, 107, 69-79.

Ha, J. (2020). The structural relationship among coach trust, athlete satisfaction, knowledge sharing, and innovative behavior toward college athletes. The Korean Journal of Sport, 18(1), 551-561.

Hong, E., Jeong, Y., \& Downward, P. (2019). Perceived organizational support, internal motivation, and work-family conflict among soccer referees. Managing Sport and Leisure, 24(1-3), 141-154.

Huh, J. (2003). Development and Validation of Athletes' SelfManagement Questionnaire(ASMQ). Korean Journal of Sport Psychology, 14(2), 95-109.

Hwang, J., \& Chun, B. (2013). The relationship among the Perfectionism, Self-management and Cognitive Performance of Korean Female Professional Golfers. Korean Journal of Sports
Science, 22(6), 615-629.

Janssen, O. (2005). The joint impact of perceived influence and supervisor supportiveness on employee innovative behaviour. Journal of Occupational and Organizational Psychology, December(78), 573-579.

Jones, R. T., Nelson, R. E., \& Kazdin, A. E. (1977). The role of external variables in self-reinforcement: A review. Behavior Modification, 1(2), 147-178.

Jöreskog, K. G., \& Sörbom, D. (2002). LISREL 8.53 for Windows. Chicago: Scientific Software International.

Jung, Y., \& Takeuchi, N. (2018). A lifespan perspective for understanding career self-management and satisfaction: The role of developmental human resource practices and organizational support. Human Relations, 71(1), 73-102.

Kang, D. (2019). Employee resilience and team effectiveness: Mediating effects of self-competency and moderating effect of perceived organizational support. Unpublished Doctoral Thesis, Daejeon University.

Kaplan, R. S., \& Norton, D. (2004). Measuring the strategic readiness of intangible assets. Harvard Business Review, February, 52-63.

Kotter, J. P., \& Heskett, J. L. (1992). Corporate culture and performance. New York: The Free Press.

Kim, D., \& Nam, K. (2020). The Relationship between instructing characteristics and athletic performance of gymnasts: focus on mediating effect of self-management. The Korean Journal of Sport, 18(2), 1039-1048.

Kim, H. (2016). Proud of our mothers in Rio. Retrieved from https:// www.korea.kr/news/cultureColumnView.do?newsId=148819893

Kim, H., \& Cruz, A. B. (2021). Psychological influence of selfmanagement on exercise self-confidence, satisfaction, and commitment of martial arts practitioners in Korea: A meta analytic approach. Frontiers in Psychology, 12, doi: 10.3389/ fpsyg.2021.691974

Kim, O., Kim, D., \& Kim, R. (2019). Relationship between selfmanagement, social support and exercise as a female soccer player. The Korean Journal of Growth and Development, 27(2), 139148.

Kim, S., Bae, S., Kim, H. G., \& Ahn, S., (2016). The effect of job crafting behavior on innovative behavior-Focused on mediating effect of work engagement. Korean Academy of Human Resource Management, 23(5), 1-26.

Ko, M., Kim, J., \& Lee, C. (2019). Moderated mediation effects of organizational trust and perceived organizational support on the link between organizational social capital and organizational effectiveness. The Korean Journal of Public Administration, 28(2), 187-223.

Kristiani, W., Matin, M., \& Sugiarto, S. (2019). The Effect of Organizational Culture and Perceived Organizational Support (POS) Towards Organizational Citizenship Behavior (OCB) Teacher SDK PENABUR Jakarta. International Journal for Educational and Vocational Studies, 1(6), 528-532. 
Lee T. Z., \& Tseng, Y. F. (2005). A study of the relationship between organizational culture and organizational effectiveness in Taiwan. Research Institute of Mathematical Sciences, 1491,161-178.

Levitt, T. (2002). Creativity Is Not Enough. Harvard Business Review, 80, 137-145.

Li, Y., Gao, Y., \& Qiao, M. (2018). Influencing factors of knowledge workers' innovation behavior based on self-management, International Conference on Humanities and Advanced Education Technology (ICHAET 2018). ISBN: 978-1-60595-577-3

Livingston, L. A., \& Forbes, S. L. (2016). Factors contributing to the retention of Canadian amateur sport officials: Motivations, perceived organizational support, and resilience. International Journal of Sports Science \& Coaching, 11(3), 342-355.

Livingston, L. A., \& Forbes, S. L. (2017). Resilience, Motivations for Participation, and Perceived Organizational Support Amongst Aesthetic Sports Officials. Journal of Sport Behavior, 40(1), 43-67.

Loi, R., Ngo, H., \& Foley, S. (2006). Linking Employees' Justice Perceptions to Organizational Commitment and Intention to Leave: The Mediating Role of Perceived Organizational Support. Journal of Occupational and Organizational Psychology, 79(1), 101-120.

Meng, J., \& Berger, B. K. (2019). The impact of organizational culture and leadership performance on PR professionals' job satisfaction: testing the joint mediating effects of engagement and trust. Public Relations Review, 45(1), 64-75.

Nam, S., \& Cheong, J. (2017). The effect of self-efficacy and job satisfaction on innovative behavior and job performance of organizational employees: mediating effect of innovative behavior. Korean Public Personnel Administration Review, 16(4), 27-55.

Ng, T. W., \& Lucianetti, L. (2016). Goal striving, idiosyncratic deals, and job behavior. Journal of Organizational Behavior, 37(1), 41-60.

Oh, B., \& Chae, H., \& Choi, M. (2019). The structural relationship between athletes' perceive POS, job satisfaction, team commitment and performance: focus on association and team POS. The Korean Journal of Sport, 17(2), 1109-1123.

Orlick, T., \& Partington, J. (1988). Mental Links to Excellence. The Sport Psychologist, 2(2), 105-130.

Paais, M., \& Pattiruhu, J. R. (2020). Effect of Motivation, Leadership, and Organizational Culture on Satisfaction and Employee Performance. The Journal of Asian Finance, Economics and Business, 7(8), 577-588.

Park, J. (2019). The relationship among ego resilience and sport response strategy of tennis players: Verification of mediating effect of self-management. The Korean Journal of Sport, 17(4), 11851196.

Platt, O. (23rd of June, 2021). What are Cristiano Ronald's diet, workout and fitness secrets? Retrieved from https://www.goal. com/en/news/cristiano-ronaldo-diet-workout-fitness-regime-realmadrid/1ez74ip78o20715bzr1947rwhi

Ratten, V. (2016). Sport innovation management: Towards a research agenda. Innovation: Management, Policy \& Practice, 18(3), 238-250.
Scott, S. G., \& Bruce, R. A. (1994). Determinants of innovative behavior: A path model of individual innovation in the workplace. Academy of Management Journal, 37(3), 580-607.

Sobel, M. E. (1986). Some new results on indirect effects and their standard errors in covariance structure models. In S. Leinhart (Ed.), Sociological Methodology (pp. 159-186). San Francisco: JosseyBass.

Son, S., \& Cho, G. (2020). Verification of relationship model among exercise passion, self-management, and exercise performance of secondary school athletes. The Korean Journal of Sport, 18(1), 563-572.

Stambulova, N. B., Engström, C., Franck, A., Linnér, L., \& Lindahl, K. (2015). Searching for an optimal balance: Dual career experiences of Swedish adolescent athletes. Psychology of Sport and Exercise, 21, 4-14.

Ströbel, T., Maier, C., \& Woratschek, H. (2018). How to reduce turnover intention in team sports? Effect of organizational support on turnover intention of professional team sports athletes. Sport, Business and Management: An International Journal, 8(2), 98117.

Svensson, P. G., Kang, S., \& Ha, J. P. (2019). Examining the influence of shared leadership and organizational capacity on performance and innovative work behavior in sport for development and peace. Journal of Sport Management, 33(6), 546-559.

Woo, H., \& Kim, M. (2021). The effects of perceived organizational support and positive psychological capital on innovative behavior: Focused on the moderating effect of creative self-efficacy. The Korean Research Association for the Business Education, 35(3), 31-59.

Yogalakshmi, J.A., \& Suganthi, L. (2020). Impact of perceived organizational support and psychological empowerment on affective commitment: Mediation role of individual career selfmanagement. Current Psychology, 39, 885-899. 


\section{고등학교 축구 선수들이 인지한 조직후원인식이 혁신성과에 미치는 영향: 자기관리의 매개효과를 중심으로}

홍은아 ${ }^{1}$, 정예지 ${ }^{2}$

1 이화여자대학교 부교수

2 유한대학교 조교수

[목적] 본 연구의 목적은 고등학교 축구 선수들이 인지한 조직후원인식이 혁신성과에 미치는 영향력을 검증하는데 있다. 더 나아가 그 과정에서 선수들의 자기관리가 매개 역할을 하는지 살펴보고자 하였다.

[방법] 회수한 137 부의 설문지 중 130부를 최종 분석에 활용하였다. 자료 분석은 Lisrel 9.2를 활용한 확인적 요인분석과 SPSS 21.0을 이용한 회귀분석을 실시하였다.

[결과] 첫째, 선수들이 인지한 조직후원인식이 자기관리에 긍정적 영향을 미치는 것으로 나타났다. 둘째, 선수들의 자기 관리는 혁신성과에 긍정적 영향을 미치는 것으로 나타났다. 마지막으로 선수들의 자기관리 정도는 조직후원인식과 혁신 성과와의 관계를 완전매개하는 것으로 나타났다.

[결론] 본 연구의 결과는 조직후원인식을 통한 자기관리의 극대화가 고등학교 축구 팀 선수들의 혁신성과로 이어질 수 있 음을 시사한다.

주요어

조직후원인식, 혁신성과, 자기관리, 고등학교 축구선수 